\section{An Analysis of Floral Consumption Values and Their Difference for Genders and Geographic Regions}

\author{
Tzu-Fang Yeh ${ }^{1,3}$ and Li-Chun Huang ${ }^{2,4,5}$
}

ADDITIONAL INDEX WORDS. factor analysis, discriminant analysis, consumer value, floral, flowers

SUMMARY. Studying the value of consumption is believed to have diagnostic value in the analysis of consumer choice behavior and, therefore, is helpful in improving the efficiency of the market. The objective of this study was to identify the consumption value that consumers seek from floral products, while also clarifying the context of that consumption value. A total of 644 valid questionnaires from a consumer survey were used for the statistical analysis. The statistical results of the factor analysis revealed that sensory hedonics, emotion conditioning, curiosity fulfillment, monetary worth, and showing care to others were the main types of the consumption value in relation to floral products. Different consumer groups were found to emphasize different types of floral consumption value. Female consumers reveal a stronger demand for the value of emotion conditioning and curiosity fulfillment, while male consumers are more likely to seek the value of sensory hedonics. Consumers in rural areas reveal a stronger demand for the value of curiosity fulfillment and monetary worth, while the consumers in urban areas reveal a stronger demand for the value of emotion conditioning, with regard to the consumption value of flowers. The study results provide florists with the key value points as they seek to increase the attraction of floral products to consumers.

$\mathrm{C}$ onsumption value is particularly important due to its ability in helping explore why consumers choose a particular product in their purchase decision. Such capability provides marketers with a diagnostic value for the analysis of consumer behavior and therefore enables the marketers to influence the consumers' purchase choice, in addition to helping the marketers in product positioning and differentiation (Friedmann, 1986; Sheth et al., 1991a). To enhance market efficiency, it is essential for marketers to clearly know the consumption value that consumers place on alternative products.

Ligas (2000) proposed that products provide value to consumers in accomplishing specific acts. Meanwhile, possessing or using a specific product also reveals the meaning of

We thank Neal E. De Vos, Charles R. Hall, and the anonymous reviewers for their review and insightful comments on an earlier version of this manuscript.

${ }^{1}$ Department of Human Resource and Public Relations, Da-Yeh University, Changhua, 51591, Taiwan

${ }^{2}$ Department of Bio-Industry Communication and Development, National Taiwan University, No. 1, Sec. 4, Roosevelt Road, Taipei, 10617, Taiwan

${ }^{3}$ Former Graduate Student.

${ }^{4}$ Assistant Professor.

${ }^{5}$ Corresponding author. E-mail: lihuang@ntu.edu.tw. self-identification or self-extension for consumers. In other words, products reveal value in terms of their functional meaning and symbolic meaning for consumers. Usually, consumers pursue the purchase alternative that has sufficient meaning to fit in with the consumers' purchasing goal.

Hirschman and Holbrook (1982) explained consumer behavior based on the aspect of sensory hedonics in that consumers consume certain goods to gain experiences from multisensory images, fantasies, and emotional arousal in using products instead of the utilitarian function of the products. In addition to the symbolic meanings and hedonic response, Friedmann (1986) concluded that consumption also reflected the consumers' consciousness in terms of the aesthetic criteria related to the products. In aesthetic consumption, consumers attend to, perceive, and appreciate a product for its beauty, without regard to its utilitarian function or benefits.

Sheth et al. (1991a, 1991b) integrated various consumption disciplines proposed by academicians in economics, marketing, clinical psychology, and social psychology and proposed that there are five consumption values that influence consumers' purchasing choices. These five consumption values are functional value, social value, emotional value, epistemic value, and conditional value. Functional value is perceived as an alternative's capacity for functional, utilitarian, or physical performance; the social value of an alternative refers to the choice imagery acquired from an alternative's association with one or more specific social groups; emotional value refers to the utility acquired from an alternative to arouse feelings or affective states; epistemic value indicates an alternative's utility to arouse curiosity, provide novelty, or satisfy a desire for knowledge; and conditional value is the perceived utility acquired from an alternative that is contingent upon a specific situation or set of circumstances. These five values are said to influence the consumers' choice to buy or not to buy, as well as the choice of product type and brand of a choice alternative.

Many studies have been conducted to help us better understand consumers' behavior in the floral market, but systematic research on the consumption value that consumers hold in relation to floral products still attracts little attention. However, the results of previous studies that aim to deal with the reasons why consumers purchase flowers may provide us with some cues regarding the consumption value of flowers. For example, Kim et al. (1999) found that there are different reasons why consumers purchase flowers, such as to decorate their homes or offices, or to celebrate a special event or moment. Flowers used for home decoration are able to improve the atmosphere of home and thus bring the sense of selfrespect to the homemakers (Oppenheim, 1996). Flowers may sometimes be purchased simply for personal habit or enjoyment (Kim et al., 1999). Due to the associated social symbolism, flowers are also purchased as gifts to facilitate the social link. For example, consumers purchase flowers for traditional holidays, such as Mother's Day and Valentine's Day, to show their care for others (Libbon, 2000). The results of such studies indicate that flowers reveal the value of the utilitarian function (e.g., for home or office decoration or for 
celebration), psychological function (e.g., bringing a sense of self-respect), the emotional function (e.g., for habit satisfaction or for personal enjoyment), and the social value (e.g., using flowers as gifts to improve social network connections) for consumers.

With the conceptualization of consumption value theory based on Sheth et al. (1991a), Oppenheim (2000) used the factors of consumption value to identify the market segment that was most likely to purchase flowers for home decoration. The results of the study revealed that the consumers who were more likely to purchase flowers for home decoration were more likely to buy flowers for a spiritual lift, to associate flowers with seasons, and who liked to arrange unusual flowers. Obviously, the consumers who like to purchase flowers for home decoration pursue the emotional value, the occasional value, and the epistemic value from the flowers they purchase. Baourakis et al. (2000) found that light users of flowers especially prefer to purchase new kinds of plants compared with general flower consumers. In addition, light users seek plants that have a minimal need for water and are resistant to diseases or to unfavorable environments. Apparently, different consumer groups look for different value from flowers.

Theoretically, the consumption value that consumers attach to a product includes functional value (Ligas, 2000; Sheth et al., 1991a), emotional value (Friedmann, 1986; Hirschman and Holbrook, 1982; Sheth et al., 1991a), social value (Ligas, 2000; Sheth et al., 1991a), epistemic value (Sheth et al., 199la), and conditional value (Sheth et al., 1991a). However, what the real context of the functional value, emotional value, social value, epistemic value, and/or conditional value is for the consumers who purchase flowers remains unknown, even though some phenomena related to the consumption value of flowers have been implied. This study intends to address this deficiency. The objectives of this study are to identify the consumption value that the consumers derive from the floral products and to clarify the context of the consumption value identified. Because gender and geographical differences have been shown to influence consumer behavior in the floral market in terms of their effect on consumer preferences, price perception, and retail channel choice (American Floral Endowment, 1992; Rhodus, 1989; Robertson and Chatfield, 1982), the difference in the floral consumption value is also compared in this study for consumer groups of people of different genders and geographical areas.

\section{Methodology}

Questionnaire Design. A questionnaire was developed as the instrument for data collection. The questions were created based on the results of previous studies that imply the potential consumption value of the purchases of flowers. The conceptualizations of consumption value theory (Sheth et al., 1991a, 1991b), hedonic consumption (Hirschman and Holbrook, 1982; Holbrook and Hirschman, 1982), the hierarchical model of consumer goals (Ligas, 2000 ), and the aesthetic criteria for consumption (Friedmann, 1986) were used to judge the validity of the context of the questionnaire. In other words, when any of the results of previous studies implied the meaning of the consumption value of flowers, their framework was extracted and worded into the questions in the questionnaire. Therefore, the content validity of the questionnaire was secured for the measurement of the consumption value that consumers hold for flowers.

In total, 39 questions were developed for the first version of the questionnaire. A pilot study was conducted at the beginning of May 2006 that 92 valid questionnaires were gained to test the validity of the questionnaire. Any questionnaire item that was unable to identify the difference of the participants' responses was deleted. Questionnaire items that did not load on any factor or had the absolute value of factor loading not greater than 0.3 in factor analysis were also deleted. As a result, 33 questions were accepted for the final version of the questionnaire. The data were recorded with the participants' agreement regarding the statements made in response to these questions using a five-point Likert scale $(1=$ extremely disagree, $2=$ disagree, $3=$ neutral, $4=$ agree, $5=$ extremely agree). Socioeconomic data in relation to the participants, including age, gender, income, education, and occupation, were also collected using a category scale.

SAMPLING. Participants were sampled from the main cities of Taiwan, including Taipei, Taichung, and Kaohsiung. Participants sampled from these cities represent the consumer population who live an urban life style in Taiwan. To compare the differences in the consumption values of the consumer groups in the urban areas and rural areas, consumers living a rural life style were also recruited. Participants who were representative of the consumer population living a rural life style were sampled from the rural counties around Taipei, Taichung, and Kaohsiung, including the counties of Taipei, Taoyuan, Changhwa, Nantou, Chiayi, and Tainan. All of the participants were sampled with purposive sampling taking place in the public sites such as department stores, train stations, science parks, markets, campuses, post offices, and gas stations of the urban cities or rural counties described above.

The survey was conducted between 19 May and 15 June 2006. Participants were first informed with a consent letter stating the purpose of the survey, and security was guaranteed that their responses would be used for academic purposes only. Most of the participants took $\approx 10$ to $15 \mathrm{~min}$ to complete the questionnaire. A total of 677 consumers participated in this study. With the exclusion of 33 incomplete questionnaires, 644 valid questionnaires were used in the statistical analysis, with 313 being sampled from urban cities and 331 from rural counties.

Statistical analysis. The data were analyzed using factor analysis to extract the main factors underlying the consumption value that consumers attached to the floral products. Each value factor generated was then named and illustrated according to the structure of its component variables. The factor scores for each value factor were summated from the relative component variables with the regression function nested in the process of factor analysis. These factor scores were the composite measure of the participants' responses to the extracted value factors. Discriminant analysis was then used to identify the main differences between the gender groups, as well as the geographic 
groups (rural area vs. urban area) for the consumption value of flowers. All statistical analyses were processed using SPSS (version 15.0; SPSS, Inc., Chicago).

\section{Results}

\section{Portrait of samples}

About $63.2 \%$ of the participants were women and $36.8 \%$ were men. The age distribution was 18 to 25 years of age $(17.9 \%), 26$ to 35 years (42.1\%), 36 to 45 years $(20.3 \%), 46$ to 55 years $(16.3 \%), 56$ to 65 years $(3.0 \%)$, and over 65 years $(0.3 \%)$. About $0.2 \%$ of the participants did not provide their age information.

The distribution of highest educational level was graduate school (11.0\%), college or university undergraduate $(63.7 \%)$, senior high school (18.9\%), junior high school (3.4\%), and elementary school $(3.0 \%)$.

Participants' occupations were as follows manufacturing $(8.9 \%)$; commercial business (18.9\%); civil servant, military service, and education (18.9\%); agriculture, forestry, fishing, and animal husbandry workers (1.1\%); students $(7.9 \%)$; service industry $(27.6 \%)$; housekeeping $(5.3 \%)$; self-employed $(4.3 \%)$; and others $(6.7 \%)$. A total of $0.3 \%$ of the participants did not indicate their occupation.

About $16.6 \%$ of the participants reported that they had a monthly income of less than (in New Taiwanese dollars) 20,000; 20,000 to $40,000(50.2 \%) ; 40,001$ to 60,000 $(21.1 \%) ; 60,001$ to $80,000(7.9 \%)$; 80,001 to $100,000(2.6 \%)$; and over $100,000(0.9 \%)$. About $0.6 \%$ of the participants did not provide their income information.

\section{The consumption value of flowers}

Before the factor analysis was processed to extract the main factors underlying the consumption value that consumers have for floral products, the factorability of data were examined using Bartlett's test of sphericity and the Kaiser-MeyerOlkin measure of sampling adequacy (MSA). Bartlett's test of sphericity is significant at the level of $\alpha=0.05\left(\chi^{2}\right.$ $=8015.84, P=0.000)$, and the overall MSA value is 0.92 . Both statistical results demonstrate the suitability of applying factor analysis to this data set (Hair et al., 1998). Meanwhile, the MSA value for each variable is larger than $0.50(0.664-0.958)$, indicating that all of the 33 variables were suitable for the factor analysis (Hair et al., 1998).

Factor analysis was processed with principle component analysis and varimax rotation. To judge whether a variable was qualified to be a latent factor in the factor analysis, the following criteria were used to determine the component variables for each factor extracted: 1) the absolute value of factor loading is equal to or greater than $0.4 ; 2$ ) a variable with high loadings on several factors is deleted; 3) a variable that does not load on any factor is deleted (Hair et al., 1998). Once any variable was deleted, the factor analysis was reprocessed with the retained variables to gain a new factor model (Hair et al., 1998). As a result, five fundamental factors of the consumption value for flowers were extracted with eigenvalue $>1$. According to the context of the component variables, these five value factors were referred to as "sensory hedonics," "emotion conditioning," "curiosity fulfillment," "monetary worth," and "showing care to others." They represent the underlying pattern of the consumption value that consumers have for flowers (Table 1).

SENSORY HEDONICS. The first value is composed of the variables "I like to touch flowers and feel satisfied with the touch," "flowers always provide me with olfactory enjoyment," "touching flowers can lift up my spirit," "the smell of flowers makes me feel good," and "I enjoy food with flowers in the recipe." These component variables illustrate the phenomenon whereby consumers perceive the value of flowers based on the sensory joy aroused by the flowers. It is through the sensory stimulation caused by touching, smelling, or tasting flowers that consumers feel happy, pleased, or satisfied. Thus, the first factor related to the consumption value of flowers was referred to as "sensory hedonics." The analysis of the rotation sums of the squared loadings in the factor analysis showed that this value factor accounted for about $18.91 \%$ of the total variance of the floral consumption value. In other words, $18.91 \%$ of the variance of the consumption value that consumers have for flowers can be explained by the value attached to sensory hedonics.
Emotion conditioning. The second value was concerned with the variables "flowers give me a feeling of joy," "flowers give me a feeling of peace," and "flowers make me feel happy." The context of the component variables illustrates the interaction between the consumer's mind and flowers. It describes the emotional side of flower consumption. Flowers can condition the consumer's mind or spirit, and make the consumer feel happy, good, and joyful. More often than not, flowers bring consumers a calm and delighted mind, and make them feel good. Apparently, flowers reveal the utility of conditioning the consumer's mind. With the meanings of its component variables, this value factor was referred to as "emotion conditioning." It accounted for $13.83 \%$ of the total variance in the consumption value of flowers.

Curiosity Fulfillment. The subsequent value consisted of the variables "unique flowers always attract my interest," "I have a greater intention to purchase new or special flowers," and "I am interested in buying the flowers that I have never seen before." Obviously, consumers also rate the value of flowers according to their novelty, as well as their capacity to stir up curiosity. Such a value has been referred to as "curiosity fulfillment" in this study, and it accounts for $12.84 \%$ of the total variance in terms of the consumption value of flowers.

The value of curiosity fulfillment described in this study is similar to the epistemic value described by Sheth et al. (1991b). They described the value of an alternative in providing novelty, arousing curiosity, and/or satisfying knowledge-seeking desire as epistemic value. Because individuals have the basic instinct to keep their life at the optimal level of stimulation, consumers are usually attracted to something new, curious, or complex. Such conceptualization implies that the purchases driven by epistemic value are simply motivated by an innate desire for getting something new or different, and are not derived from satisfying current needs (Sheth et al., 1991b).

Monetary worth. The fourth value factor was extracted with the component variables of "the price of flowers is reasonable," "the quality of flowers is good," and "the longevity 
Table 1. Summary of the factor analysis performed to extract the consumption value that consumers have for floral products based on 644 valid questionnaires surveyed in Taiwan between 19 May and 15 June 2006.

\begin{tabular}{|c|c|c|c|}
\hline Component variables & $\begin{array}{l}\text { Factor } \\
\text { loadings }\end{array}$ & $\begin{array}{c}\text { Validity } \\
(\text { Cronbach's } \alpha)\end{array}$ & $\begin{array}{l}\text { Extracted } \\
\text { consumption } \\
\text { value for the } \\
\text { floral products }\end{array}$ \\
\hline I like to touch flowers and feel satisfied with the touch. & 0.764 & 0.832 & Sensory hedonics \\
\hline Flowers always provide me with olfactory enjoyment. & 0.764 & & \\
\hline Touching flowers can lift up my spirit. & 0.729 & & \\
\hline The smell of flowers makes me feel good. & 0.729 & & \\
\hline I enjoy food with flowers in the recipe. & 0.701 & & \\
\hline Flowers give me a feeling of joy. & 0.837 & 0.813 & Emotion conditioning \\
\hline Flowers give me a feeling of peace. & 0.802 & & \\
\hline Flowers make me feel happy. & 0.769 & & \\
\hline Unique flowers always attract my interest. & 0.802 & 0.754 & Curiosity fulfillment \\
\hline I have a greater intention to purchase new or special flowers. & 0.764 & & \\
\hline I am interested in buying the flowers that I have never seen before. & 0.747 & & \\
\hline The price of flowers is reasonable. & 0.745 & 0.551 & Monetary worth \\
\hline The quality of flowers is good. & 0.736 & & \\
\hline The longevity of flowers is good. & 0.654 & & \\
\hline $\begin{array}{l}\text { Flowers can be used to represent blessing or convey wishes } \\
\text { to friends on occasions of celebration or sorrow. }\end{array}$ & 0.864 & 0.661 & Showing care to others \\
\hline $\begin{array}{l}\text { Flowers can be used to represent best wishes when visiting } \\
\text { someone who is hospitalized. }\end{array}$ & 0.818 & & \\
\hline
\end{tabular}

of flowers is good." The structure of the component variables indicates that consumers also evaluate the value of flowers based on their physical performance, such as their quality and longevity. Meanwhile, the value of such physical performance is transformed into the amount of money people are prepared to pay. Obviously, there is a rational side for the consumption of flowers. According to its component variables, this value factor was referred to as "monetary worth" in this study to highlight the value of money spent on purchases of flowers, which was evaluated according to how good the physical performance of the flowers purchased was. The physical performance of an alternative usually relies on the attributes it has. Therefore, this factor is likely to influence consumers upon choosing the floral products that possess the most attributes to enable their purchases to perform their best in terms of their salient utilities. What kinds of attributes serve as the criteria in the purchase choice of flowers will depend on the beliefs of the purchasers (Sheth et al., 1991b). The analysis of rotation sums of squared loadings performed in the factor analysis showed that this value factor accounts for about $10.20 \%$ of the total variance in terms of the consumption value of flowers.
Showing care to others. The last value was extracted based on the variables "flowers can be used to represent blessing or convey wishes to friends on occasions of celebration or sorrow," and "flowers can be used to represent best wishes when visiting someone who is hospitalized." The component variables for this value factor indicate the functional utility of flowers in that flowers are used as a gift to serve a role in communicating care between the dyads of the givers and recipients of flowers. Thus, this value is referred to as "showing care to others." This is consistent with the results of a previous study in that gift giving is one of the main product behaviors that consumers have for the floral products and it forces consumers to purchase more flowers (Huang, 2005). However, the performance of such utility relies on the learned meanings of flowers in consumers' minds. In other words, the symbolic meaning is essential for flowers to perform their role in gift giving. How the symbolic meanings are formed for a product depends on the culture and social norms of the society. Thus, how popular the flowers are in terms of showing care to others will depend on what consumers recognize as the symbolic meanings of flowers and the social norms in their society regarding the behavior of using flowers as gifts (Sheth et al., 1991b). This value factor accounts for $9.53 \%$ of the total variance of the consumption value for flowers.

\section{The difference between gender groups}

By means of simultaneous discriminant analysis, a discriminant function is formed with the consumption value extracted in this study to distinguish the difference between male and female consumers regarding to the consumption value attached to flowers. The test of Wilks' lambda indicates that the discriminant power of the discriminant function is significant $\left(\chi^{2}=17.05, P=0.004\right)$.

The statistical results showed that the difference between male and female consumers with regard to the consumption value for flowers mainly lay in the variables sensory hedonics, emotion conditioning, and curiosity fulfillment. The magnitude of the standardized discriminant coefficients indicate that the value of emotion conditioning has the most significant power to discriminate the difference between the two groups (standardized discriminant coefficient $=0.761)$, followed by the value of curiosity fulfillment $(0.426)$ and sensory hedonics $(-0.376)$, as presented in Table 2 . The group means of these variables 
Table 2. Summary of the discriminant analysis performed to clarify the difference in the consumption value attached to floral products between male and female consumers based on 644 valid questionnaires surveyed in Taiwan between 19 May and 15 June 2006.

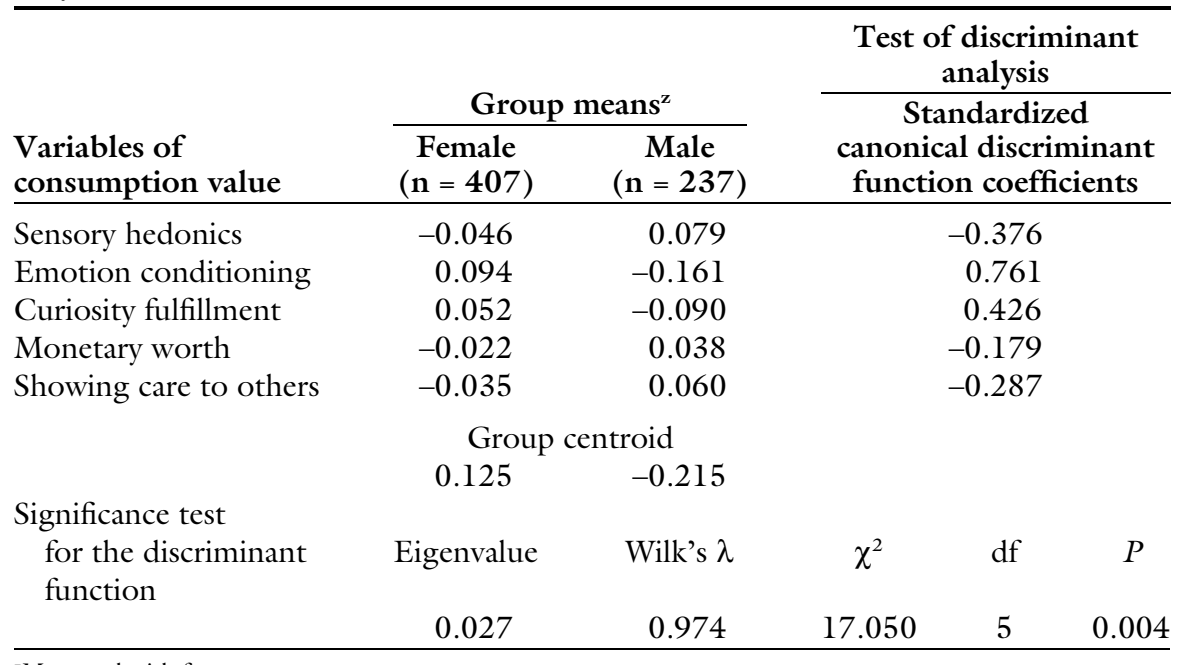

${ }^{\mathrm{z}}$ Measured with factor scores.

indicate that female consumers reveal a stronger demand for the value of emotion conditioning and curiosity fulfillment with regard to the flower consumption, while male consumers are more likely to seek the value of sensory hedonics.

Because the standardized discriminant coefficients for the value of monetary worth and showing care to others are low (Table 2), these two value factors have less power to discriminate the difference between male and female consumers. Apparently, the two groups have similar attitudes toward the value of monetary worth, as well as the social value of showing care to others through flower consumption.

\section{The difference between geographic groups}

The discriminant analysis was processed using the simultaneous estimation method to form a discriminant function for the difference in the consumption values for flowers between the consumer groups in urban areas versus rural areas. Wilks' lambda test indicates that the discriminant power of the discriminant function does not seem significant at $\alpha=0.05$ level $\left(\chi^{2}=10.94, P=0.053\right)$. When engaging in discriminant analysis, some statisticians suggest that the significance level should be determined with regard to the synergy of the cost of inappropriate judgments versus the value of the information obtained from statistical analysis. In considering the total synergy, a higher critical level as $\alpha=0.10$ or more is suggested to determine its significance for a discriminant function. Sometimes, the critical level may be retained at 0.2 or even 0.3 (Hair et al., 1998). Based on these suggestions, the discriminant function generated in this section was accepted as significant for discriminating the difference in the floral consumption value between the consumer groups in urban areas versus rural areas.

The statistical results in this section indicate that the main differences between the consumers in urban areas versus those in rural areas with regard to the consumption value for flowers mainly lay in the variables emotion conditioning, curiosity fulfillment, and monetary worth. The standardized discriminant coefficients indicate that the value of curiosity fulfillment has the most significant power to discriminate the differences between these two groups of consumers (standardized discriminant coefficient $=0.773$ ), followed by the value of monetary worth $(0.410)$ and emotion conditioning $(-0.384)$, as indicated in Table 3 . The group means of the variables reveal that the consumers in rural areas reveal a stronger demand for the value of curiosity fulfillment and monetary worth, while the consumers in urban areas reveal a stronger demand for the value of emotion conditioning with regard to the consumption value of flowers.

The magnitudes of the discriminant coefficients for sensory hedonics and showing care to others are low. This means that there is no significant difference between the consumers in urban areas versus rural areas regarding the value of sensory hedonics and showing care to others when they purchase flowers.

\section{Discussion and conclusion}

The statistical results indicate that the consumption value that consumers attach to floral products is mainly composed of the value of sensory hedonics, emotion conditioning, curiosity fulfillment, monetary worth, and showing care to others. This finding is consistent with the conceptualization of consumer value creation proposed by Smith and Colgate (2007). According to Smith and Colgate's proposition, the sensory value, emotional value, social value, and epistemic value are the key parts of the total consumer experiential value toward the products purchased and/or used. It implies that sensory hedonics, emotion conditioning, curiosity fulfillment, and showing care to others as defined in this study reflect what consumers feel and experience in their consumption of flowers. These value variables provide florists with the necessary perception regarding value creation to increase the attractiveness of flowers to consumers.

Sensory hedonics and emotion conditioning are important values to consumers in purchasing flowers. Both value factors explain a total $32.74 \%$ of the variance of the consumption value attached to floral products (sensory hedonics, $18.91 \%$ and emotion conditioning, 13.83\%). The value of sensory hedonics makes florists aware of the importance of sensory stimulation for the sale of flowers. Attributes of the floral products should be able to provoke the sensory pleasure of vision, olfaction, and/or texture for consumers. Such value adding helps to shape positive experiences, leading to the purchase or use of flowers by consumers.

As well, sensory hedonics and emotion conditioning are possibly interrelated. Based on the theory of hedonic consumption, sensory 
Table 3. Summary of the discriminant analysis performed to clarify the difference in the consumption value attached to floral products between the consumers in urban areas and those in rural areas based on 644 valid questionnaires surveyed in Taiwan between 19 May and 15 June 2006.

\begin{tabular}{|c|c|c|c|c|c|}
\hline \multirow[b]{2}{*}{$\begin{array}{l}\text { Variables of } \\
\text { consumption } \\
\text { value } \\
\end{array}$} & \multicolumn{2}{|c|}{ Group means ${ }^{\mathrm{z}}$} & \multicolumn{3}{|c|}{$\begin{array}{c}\text { Test of discriminant } \\
\text { analysis }\end{array}$} \\
\hline & $\begin{array}{c}\text { Residents of } \\
\text { urban areas } \\
(\mathrm{n}=\mathbf{3 1 3})\end{array}$ & $\begin{array}{c}\text { Residents of } \\
\text { rural areas } \\
(\mathbf{n}=\mathbf{3 3 1}) \\
\end{array}$ & \multicolumn{3}{|c|}{$\begin{array}{c}\text { Standardized } \\
\text { canonical discriminant } \\
\text { function coefficients }\end{array}$} \\
\hline Sensory hedonics & -0.013 & 0.013 & \multicolumn{3}{|c|}{0.100} \\
\hline $\begin{array}{l}\text { Emotion } \\
\text { conditioning }\end{array}$ & 0.051 & -0.048 & \multicolumn{3}{|c|}{-0.384} \\
\hline Curiosity fulfillment & -0.103 & 0.097 & \multicolumn{3}{|c|}{0.773} \\
\hline Monetary worth & -0.054 & 0.052 & \multicolumn{3}{|c|}{0.410} \\
\hline $\begin{array}{l}\text { Showing care to } \\
\text { others }\end{array}$ & 0.039 & -0.037 & \multicolumn{3}{|c|}{-0.295} \\
\hline \multicolumn{6}{|c|}{ Group centroid } \\
\hline \multirow{3}{*}{$\begin{array}{l}\text { Significance test } \\
\text { for discriminant } \\
\text { function }\end{array}$} & -0.135 & 0.128 & & & \\
\hline & Eigenvalue & Wilk's $\lambda$ & $\chi^{2}$ & $\mathrm{df}$ & $P$ \\
\hline & 0.017 & 0.983 & 10.940 & 5 & 0.053 \\
\hline
\end{tabular}

${ }^{\mathrm{z}}$ Measured with factor scores.

stimulation is said to be the antecedent for emotion arousal (Hirschman and Holbrook, 1982). That is, sensory hedonics stimulated by the floral products may arouse certain positive emotions for the users of flowers, thus, the spirit of the flower users is conditioned. Clearly, sensory hedonics seems to be crucial regarding the creation of consumer value in the retail market of flowers. The attributes of the floral products that are able to create the sensory pleasure for the floral consumers are very likely responsible for the satisfaction in terms of the consumers' demand for the value of emotion conditioning.

The study results also indicate that the epistemic value of flower consumption lies in curiosity fulfillment. It implies that novelty and uniqueness are other key points for selling flowers. Apart from bringing new products to consumers, florists can also contribute to the work of information communication with consumers regarding the satisfaction of consumer demand for curiosity fulfillment (Smith and Colgate, 2007). For example, the specialty, uniqueness, and attractiveness of the flowers should be pointed out to the consumers, and the physical mechanism for the formation of that specialty, uniqueness, and attractiveness can be fully explained to consumers using understandable terminology.

The value of showing care to others indicates the importance of sales of flowers as gifts. Based on the social psychology of gift giving, one presents gifts to convey one's selfidentity and the idea that the recipient evokes in his/her imagination. Certain social meanings, like influence, power, sympathy, status, emotion, or subordination, between the dyads of giver and recipient are nested in the behavior of gift giving (Schwartz, 1967). Therefore, when flowers are purchased as gifts, they should be able to translate such social meaning for achieving the goal of the flower users. To sell flowers in a gift market, the social symbolism of flowers needs to be firmly identified and promoted. Doing so helps to create the consistent recognition between the givers and recipients of the floral products, and thus to reinforce the role of gifts for flowers to satisfy the consumers' needs.

Previous studies have demonstrated that consumer demand for flowers is quite price-elastic (Rhodus, 1989). Such price-related behavior is also demonstrated in this study in that the statistical results of this study reveal that monetary worth is one of the component dimensions for the consumption value of flowers. Apparently, consumers think over what they gain with dollars regarding flower purchases. Some consumer groups, such as young consumers, men, and high-income consumers, are especially interested in low-priced flowers. Sometimes, consumers even choose the product with less quality, or buy smaller amounts, to save money (Prince et al., 1980). However, the influence of age on consumers' perception toward the price of flowers might be varied with nationality. In Japan, the older generation is more likely to consider the value for money than younger generation regarding flower purchases (Imanishi et al., 1992).

Generally speaking, the value of floral consumption explored in this study helps florists consider the creation of consumer value in relation to the users of flowers, including what consumers want from flowers and how to bring out the attributes of the floral products so that they satisfy the consumers' wants. Its context illustrates that the floral products need to have a strong appeal in terms of aesthetics, novelty, symbolism, and emotion to make consumers feel that they are fun, interesting, and functional.

However, because floral consumption value varies with gender and geographic region, the strategy of value creation needs to be refined in regard to market segmentation. For example, the statistical results indicate that female consumers have a stronger demand for the value of emotion conditioning and curiosity fulfillment than do male consumers, while male consumers have a stronger demand for sensory hedonics. Therefore, the use of sensory stimulation is essential for selling flowers to male customers, but the use of sensory stimulation should also be able to arouse inner emotions to fully satisfy the value demanded when selling flowers to female customers. Because women are more curious regarding flowers, the floral products with novelty, uniqueness, and well-explored information will delight the female consumers in particular. The geographic region influences the floral consumption value in that the consumers of rural regions reveal more demand for curiosity fulfillment and monetary worth than those of urban regions. As a result, price and novelty become important for selling flowers in rural areas. Similar to the value 
characteristics of female consumers, consumers of urban regions reveal a stronger demand for the value of emotion conditioning.

The consumption value explored in this study was investigated from the aspect of the product side. It is suggested that future studies should aim to construct the whole value frame that consumers have, such as the value consumers attach to the possession, use, and/or service, when purchasing flowers. Such a study will benefit the floral industry in finding more information that can be made accessible to florists. Besides, how consumers balance or trade off one value against another needs to be further investigated to increase the accuracy of consumer value creation in the floral market.

\section{Literature cited}

American Floral Endowment. 1992. Flora-stats: Research report. American Floral Endowment, Edwardsville, IL.

Baourakis, G., D. Gerasopoulos, N. Kalofolias, N. Kalogeras, and A. Zoumis. 2000. Marketing research: The case of floral products. Acta Hort. 541:227-232.

Friedmann, R. 1986. Psychological meaning of products: Identification and marketing applications. Psychology Mktg. 3:1-15.
Hair, J.F., Jr., R.E. Anderson, R.L. Tatham, and W.C. Black. 1998. Multivariate data analysis. 5th Intl. ed. Prentice Hall, Upper Saddle River, NJ.

Hirschman, E.C. and M.B. Holbrook. 1982. Hedonic consumption: Emerging concepts, methods and propositions. J. Mktg. 46(3):92-101.

Holbrook, M.B. and E.C. Hirschman. 1982. The experiential aspects of consumption: Consumer fantasies, feelings, and fun. J. Consum. Res. 9(2): 132-140.

Huang, L. 2005. Floral product behaviors and their influence on consumer floral purchase frequency. HortTechnology 15(4):766-771.

Imanishi, H., F. Yonezawa, and H. Imanishi. 1992. Psychological research on the attitude of florist customers towards flowers. J. Jpn. Soc. Hort. Sci. 60(4):981-987.

Kim, H.H., Y.J. Kyung, K. Ohkawa, C.H. Pak, and B.H. Kwack. 1999. Flower industry in Korea. Acta Hort. 482:407-414.

Libbon, R.P. 2000. Dear data dog: What does my mother expect for Mother's Day? Amer. Demogr. 22(5):25.

Ligas, M. 2000. People, products and pursuits: Exploring the relationship between consumer goals and product meanings. Psychology Mktg. 17(11): 983-1003.
Oppenheim, P.P. 2000. Segmentation and target marketing in a floral market. Acta Hort. 536:529-536.

Oppenheim, P.P. 1996. Understanding the factors influencing consumer choice of cut flowers: A means-end approach. Acta Hort. 429:415-422.

Prince, T.L., J.L. Robertson, and L.H. Chatfield. 1980. Factors affecting the marketability of roses. J. Amer. Soc. Hort. Sci. 105(3):388-393.

Rhodus, W.T. 1989. Estimating price elasticity for fresh flower bouquets sold in supermarkets. HortScience 24(2):386-387.

Robertson, J.L. and L.H. Chatfield. 1982. Fresh flower merchandising in loose bunches. HortScience 17(4):593-596.

Schwartz, B. 1967. The social psychology of the gift. Amer. J. Sociol. 73(1):1-11.

Sheth, J.N., B.I. Newman, and B.L. Gross. 1991a. Why we buy what we buy: A theory of consumption values. J. Bus. Res. 22:159-170.

Sheth, J.N., B.I. Newman, and B.L. Gross. 1991b. Consumption values and market choices: Theory and application. South-Western, Cincinnati, OH.

Smith, J.B. and M. Colgate. 2007. Consumer value creation: A practical framework. J. Mktg. Theory Practice 15(1):7-23. 